\title{
The effectiveness of interferon-alpha subtypes alternation for metastasis from renal cell carcinoma
}

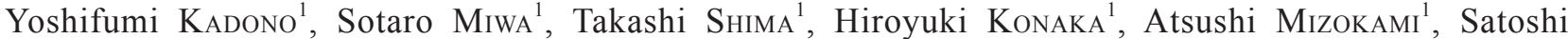 \\ Yotsuyanagi $^{2}$, Akio Hirata ${ }^{3}$, Yasukazu Takase ${ }^{4}$, Toshiaki Sugata ${ }^{4}$, Masayoshi Shimamura ${ }^{5}$, and Mikio Namiki ${ }^{1}$ \\ ${ }^{1}$ Department of Integrative Cancer Therapy and Urology, Kanazawa University Graduate School of Medical Science, Kanazawa, \\ Ishikawa; ${ }^{2}$ Department of Urology, Koseiren Takaoka Hospital, Takaoka, Toyama; ${ }^{3}$ Department of Urology, Fukui Prefectural Hospital, \\ Fukui; ${ }^{4}$ Department of Urology, FukuiKen Saiseikai Hospital, Fukui; and ${ }^{5}$ Department of Urology, Ishikawa Prefectural Central Hospi- \\ tal, Kanazawa, Ishikawa, Japan
}

(Received 27 August 2012; and accepted 18 September 2012)

\begin{abstract}
Interferon-alpha (IFN- $\alpha$ ) has been used in systemic treatment for metastatic renal cell carcinoma (mRCC). IFN- $\alpha$ has at least 14 subtypes, each of which has different biological activity. There have been reports that $\mathrm{mRCC}$ resistant to an IFN- $\alpha$ treatment responded to another IFN- $\alpha$ subtype. This study was performed to evaluate the effectiveness of alternation of different IFN- $\alpha$ subtypes for mRCC that did not respond to initial IFN- $\alpha$ treatment. In our department and associated institutions, alternating therapy of IFN- $\alpha$ was provided for 15 initial IFN- $\alpha$ refractory $\mathrm{mRCC}$ cases from June 2005 to September 2008. Among the 15 patients, the effects of alternating IFN- $\alpha$ therapy were as follows: complete response (CR), 0 cases; partial response (PR), 1 case; stable disease (SD), 3 cases; progressive disease (PD), 11 cases. The response rate (CR+PR) was $7 \%$ and disease control rate $(\mathrm{CR}+\mathrm{PR}+\mathrm{SD})$ was $27 \%$. No severe side effects were observed in any of these cases. The PR case is still in PR 21 months after alternating IFN- $\alpha$ therapy. Among the three SD cases, one has continued SD for 14 months and the other for 12 months. Alternating IFN- $\alpha$ therapy for $\mathrm{mRCC}$ can be attempted even if other cytokines are not effective.
\end{abstract}

As prospective randomized trials indicated a beneficial survival effect of interferon-alpha (IFN- $\alpha$ ) in metastatic renal cell carcinoma (mRCC) patients, IFN- $\alpha$ was adopted as the first-line treatment for mRCC (11). However, the response rate of therapy was around $15 \%(21)$, and even in combination with interleukin-2, the effect was around 20\% (15). These results in $\mathrm{mRCC}$ patients were obviously unsatisfactory. Recently, the strategy for $\mathrm{mRCC}$ is changing to administration of molecular targeted drugs instead

Address correspondence to: Yoshifumi Kadono, MD, $\mathrm{PhD}$

Department of Integrative Cancer Therapy and Urology, Kanazawa University Graduate School of Medical Science, 13-1 Takara-machi, Kanazawa, Ishikawa 920-8640, Japan Tel: +81-76-265-2393, Fax: +81-76-222-6726

E-mail: yskadono@yahoo.co.jp of immunotherapy as the first-line of therapy, and the use of IFN- $\alpha$ is recommended only in combination with bevacizumab according to the National Comprehensive Cancer Network (NCCN) and the European Association of Urology (EAU) guidelines $(5,17)$. However, to date long-term remission has been obtained by treatment with IFN- $\alpha$ alone.

There are at least 14 subtypes of IFN- $\alpha$, each of which has different biological activity (4). There are three different IFN- $\alpha$ preparations with different subtype compositions available in Japan: recombinant IFN- $\alpha 2 b$ (Intron A; Schering-Plough Pharmaceuticals Co. Ltd., Osaka, Japan), natural IFN- $\alpha$ (OIF; Otsuka Pharmaceuticals Co. Ltd., Tokyo, Japan), and Sumiferon (Dainippon Sumitomo Pharma Co. Ltd., Osaka, Japan). There have been several reports of mRCC cases that responded to treatment with one IFN- $\alpha$ preparation even though the patient 
did not respond to any other IFN- $\alpha$ subtype composition $(6,7,9,12,16)$. Here, we report the efficacy of IFN- $\alpha$ alteration therapy for cytokine-refractory mRCC.

\section{MATERIALS AND METHODS}

In our department and associated institutions, alternating IFN- $\alpha$ therapy was provided for cases of initially IFN- $\alpha$-refractory mRCC from June 2005 to September 2008. The study population consisted of patients aged $\geq 20$ years with histologically or cytologically confirmed $\mathrm{mRCC}$ who did not respond to at least one IFN- $\alpha$-containing regimen. Other inclusion criteria were as follows: life expectancy $\geq 3$ months; presence of at least one measurable lesion on computed tomography (CT) or magnetic resonance imaging (MRI) as designated by Response Evaluation Criteria in Solid Tumors (RECIST); adequate cardiac, hepatic, and renal function; no active infection. Performance status and risk classification were assessed based on the Karnofsky performance status scale and the Memorial Sloan-Kettering Cancer Center (MSKCC) prognostic factor model, respectively. Informed consent was obtained from all patients prior to enrollment in the study, which was approved by the institutional review board at each participating hospital.

In cases in which medication was discontinued due to confirmation of progressive disease (PD) or side effects in the previous treatment, IFN- $\alpha$ with a subtype composition different to that of the previous IFN- $\alpha$ preparation was administered after an interval of 2 weeks. The doses of IFN- $\alpha$ were entrusted to each doctor in charge and intervals were a minimum of twice a week. Treatment was canceled in cases in which PD or side effects were confirmed after administration of IFN- $\alpha$.

Serum C-reactive protein (CRP) and interleukin (IL)-6 levels were measured before and every 2 months after IFN- $\alpha$ administration for the initial 6 months. Serum CRP was measured in the laboratory of Kanazawa University Hospital and IL-6 was measured by chemiluminescent enzyme immunoassay (SRL Inc., Tokyo, Japan). The cutoff value of serum CRP level in our hospital is $0.3 \mathrm{mg} / \mathrm{dL}$.

All patients routinely underwent physical examination and laboratory evaluation every 2 to 4 weeks. The responses of all patients were assessed by CT of the chest and abdomen every 2 months for 6 months after changing IFN- $\alpha$, and then every 3 months according to RECIST. The response was categorized based on the maximum effect of immu- notherapy from the time of protocol entry. Treatment was continued in cases exhibiting either a response or stable disease (SD) until disease progression was observed. The adverse events associated with administration of IFN- $\alpha$ to the patients were assessed by the National Cancer Institute Common Terminology Criteria for Adverse Events (NCICTCAE) ver.3. The differences in serum IL-6 and $\mathrm{CRP}$ in the partial response (PR), SD, and PD groups were analyzed by Mann-Whitney U-test. Correlations between serum IL-6 and CRP levels were determined by Spearman's rank correlation test, and $P<0.05$ was considered to indicate statistical significance.

\section{RESULTS}

The characteristics of the 15 patients included in this study are summarized in Table 1. Histological

Table 1 Patient characteristics $(n=15)$

\begin{tabular}{|c|c|}
\hline \multicolumn{2}{|l|}{ Age (years) } \\
\hline Median & 63 \\
\hline Range & $44-76$ \\
\hline \multicolumn{2}{|l|}{ Gender } \\
\hline Male & 14 \\
\hline Female & 1 \\
\hline \multicolumn{2}{|l|}{ Karnofsky performance status } \\
\hline 80 or grater & 13 \\
\hline Less than 80 & 2 \\
\hline \multicolumn{2}{|l|}{ Nephrectomy } \\
\hline Yes & 14 \\
\hline No & 1 \\
\hline \multicolumn{2}{|l|}{ Pathological results } \\
\hline Clear cell cancer & 15 \\
\hline \multicolumn{2}{|l|}{ Metastatic lesions } \\
\hline Lung only & 8 \\
\hline Lymph node only & 1 \\
\hline Multiple & 6 \\
\hline \multicolumn{2}{|l|}{ Previous treatment } \\
\hline IFN- $\alpha$ only & 10 \\
\hline Sumiferon & 7 \\
\hline OIF & 2 \\
\hline Intron A & 1 \\
\hline IFN- $\alpha$ (Sumiferon), IL-2 & 3 \\
\hline IFN- $\alpha$ (Sumiferon), 5-FU & 1 \\
\hline IFN- $\alpha$ (Sumiferon), IL-2, 5-FU, mini-transplantation & 1 \\
\hline \multicolumn{2}{|l|}{ MSKCC risk criteria } \\
\hline Favorable & 3 \\
\hline Intermediate & 11 \\
\hline Poor & 1 \\
\hline
\end{tabular}

IFN- $\alpha$, interferon-alpha; IL-2, interleukin-2; 5-FU, 5-fluorouracil; MSKCC, Memorial Sloan-Kettering Cancer Center 
examination indicated that all cases showed clear cell type RCC (14 cases with previous nephrectomy specimen and 1 case with cervical lymph node biopsy specimen). With regard to metastases, 6 cases had multiple organ metastases and 9 cases had metastasis in only 1 organ. First induction of IFN- $\alpha$ therapy had been performed in all patients. The study population included several patients who had received various treatments, including immunotherapy, mini-transplantation (i.e., reduced stem cell transplantation), and chemotherapy. As a change from the previous treatment, 13 cases were administered OIF and 2 cases received Sumiferon.

With regard to adverse events, administration was discontinued in 1 case because of exacerbation of depression, but there were no other cases in which treatment was discontinued due to side effects.

Confirmed PR according to RECIST was observed in one patient $(7 \%)$ and the response rate (CR+PR) was 7\% (Table 2). A total of 3 patients achieved SD and the overall disease control rate $(\mathrm{CR}+\mathrm{PR}+\mathrm{SD})$ was $27 \%$ (Table 2). The PR case had pulmonary and lymph node metastases and all SD cases had only pulmonary metastasis. The case of PR is still in PR after 21 months. Two of the 3 cases of SD still had SD after 14 months and 12 months, respectively. The other case of SD dropped out due to exacerbation of depression after 4 months administration of altered IFN- $\alpha$.

In all disease control cases, the serum IL-6 levels before treatment were lower than $2 \mathrm{pg} / \mathrm{mL}$ and were significantly lower than the levels in PD cases (Fig. 1). The serum IL-6 levels showed almost no changes after alternative IFN- $\alpha$ treatment in all cases. The serum CRP levels of disease control cases were all negative $(<0.3 \mathrm{mg} / \mathrm{dL})$ and a significant correlation was found between IL-6 level and CRP level $\left(\mathrm{R}^{2}=0.706 ; P=0.0001\right.$; Fig. 2$)$.

The number of MSKCC risk factors in all disease control cases was 0 or 1 , and all cases with two or more risk factors were PD (Table 3).

\section{DISCUSSION}

The only effective treatment for mRCC was cytokine-based immunotherapy until recently. However, recent advances in the understanding of genetics and biology of RCC have led to novel molecular targeted agent, such as tyrosine kinase inhibitors (TKIs) or mammalian target of rapamycin (mTOR) inhibitors. The treatment strategy for $\mathrm{mRCC}$ in Europe and America has changed from cytokine therapy to molecular targeted therapy, and the cytokine therapy
Table 2 Evaluation of treatment response

\begin{tabular}{lc} 
Complete Response (CR) & 0 \\
Partial Response (PR) & 1 \\
Stable Disease (SD) & 3 \\
Progressive Disease (PD) & 11 \\
\hline
\end{tabular}

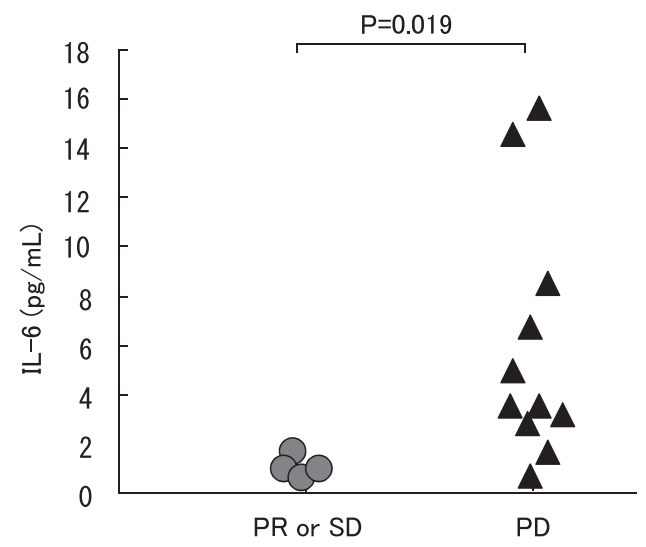

Fig. 1 Comparisons of serum interleukin (IL)-6 levels between partial response (PR) or stable disease (SD) groups and progressive disease (PD) group. The serum IL-6 levels before treatment in all disease control cases were lower than $2 \mathrm{pg} / \mathrm{mL}$ and were significantly lower than the levels in PD cases.

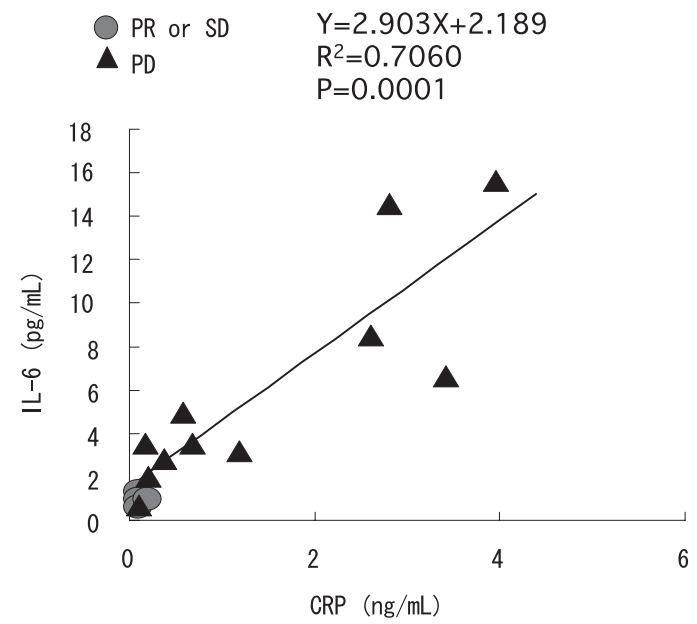

Fig. 2 Relationship between C-reactive protein (CRP) and interleukin (IL)-6 levels in partial response (PR) or stable disease (SD) groups and progressive disease (PD) group. The serum CRP levels of disease control cases were all negative $(<0.3 \mathrm{mg} / \mathrm{dL})$ and a significant correlation was found between IL-6 level and CRP level.

with IFN- $\alpha$ or IL-2 is not recommended as single therapy in the EAU or NCCN guidelines (2). However, molecular target therapy is associated with particular adverse events, such as hand-foot syndrome, 
which our urologists have not encountered. In addition, grade 3 or higher adverse events classified according to the NCI-CTCAE ver.3, including severe myelosuppression or cardiac dysfunction, are occasionally observed especially with administration of sunitinib, which usually has favorable effects in mRCC (13). Therefore, treatment often cannot be continued in patients and their quality of life suffers because of these adverse events. There have been reports that adverse events of molecular target medicine may occur more strongly in Japanese patients, which may be due to ethnic differences $(1,20)$.

The previous study analyzing treatment outcomes in 1463 Japanese mRCC patients received cytokinebased therapy indicated that the median survival time of 13.1 months in Europe and the USA was increased to 21.4 months in Japan (14). Although this was a retrospective study, it was suggested that Japanese mRCC patients live longer than those in Europe and the USA. There are various possible explanations for this difference of their life span. First, nephrectomy is performed in a higher percentage of cases in Japan. Second, there are fewer cases with multiple metastases in the Japanese population. Third, most Japanese mRCC patients continued cytokine therapy even after disease was evaluated as progressed as this was enabled by the insurance system in Japan. Finally, the differences may be related to racial differences between the European/ American and Japanese populations. Indeed, single nucleotide polymorphism (SNP) analysis of signal transducer and activator of transcription 3 (STAT3) expression indicated that the proportions of genotypes observed more frequently in IFN- $\alpha$ responders are higher in the Japanese population than in white populations (8). Therefore, the current European and American guidelines for mRCC treatments are not suitable for the Japanese population. Cytokine therapy has been shown to be effective especially in cases with metastases of the lung only. It is necessary to accumulate data in Japan and to form new guidelines for use in the Japanese population. Immunotherapy may be suitable as first-line treatment only in cases with metastases to the lungs and lymph nodes from RCC.

There are some differences in subtype compositions among recombinant and natural IFN- $\alpha$ preparations because of differences in manufacturing methods (Table 4). Yanai et al. characterized the antitumor activities of various IFN- $\alpha$ subtypes (IFN- $\alpha$ $1,2,5,8$, and 10) on RCC cell lines in vitro, and showed that IFN- $\alpha 8$ had the most potent inhibitory activity against cell proliferation among these sub-
Table 3 Relation between numbers of poor prognosis factors and treatment response

\begin{tabular}{lllll}
\hline & \multicolumn{5}{c}{ Number of poor prognosis risk factors } \\
\cline { 2 - 5 } & 0 & 1 & 2 & 3 \\
\hline PR or SD $(\mathrm{n}=4)$ & 2 & 2 & 0 & 0 \\
PD $(\mathrm{n}=11)$ & 1 & 4 & 5 & 1 \\
\hline
\end{tabular}

$\mathrm{PR}$, partial response; $\mathrm{SD}$, stable disease; $\mathrm{PD}$, progressive disease.

Table 4 Characterization of each interferon alpha preparations

\begin{tabular}{lccc}
\hline & Intron A & Sumiferon & OIF \\
\hline type & recombinant & native & native \\
subtype & 2 & $1,2,5,8,10$ & $2,7,8$ \\
production cell & E.coli & NAMALWA & BALL-1 \\
Sugar chain (IFN-alpha2) & - & + & + \\
\hline
\end{tabular}

INF, interferon

types (23). On the other hand, Yamaoka et al. examined the effects of IFN- $\alpha$ subtypes (IFN- $\alpha 1,2,5,7$, $8,10,14,17$, and 21) produced by NAMALWA cells on the human RCC cell line ACHN, and showed that IFN- $\alpha 10$ had the strongest inhibitory effect against ACHN cell proliferation with affinity to ACHN cells that was 10 times higher than that of IFN- $\alpha 2$ (22).

The antiproliferative effects of both natural and recombinant IFN- $\alpha 2$ are dependent on the target cell line. The differences between natural and recombinant IFN- $\alpha 2$ may be because the former is glycosylated while the latter is not (Table 4) (24). Treatment with other IFNs, such as purified natural IFN- $\alpha$, may be useful in cases of hairy-cell leukemia that develop clinical resistance to recombinant IFN- $\alpha 2$ because of the presence of anti-IFN neutralizing antibody (18). Horiguchi and Uchida reported a case of mRCC that showed a good response to natural IFN- $\alpha$ (OIF) for a long time, even after the patient did not respond to another IFN- $\alpha$ (Sumiferon) (7). Oya et al. reported a $\mathrm{mRCC}$ case that the change from recombinant IFN- $\alpha 2 b$ (Intron A) to natural IFN- $\alpha$ (OIF) was effective (16). We also encountered a mRCC case that the change from a natural IFN- $\alpha$ (OIF) to another natural IFN- $\alpha$ (Sumiferon) was effective, and the PR status had continued for over 21 months (12). These observations suggest that each $\mathrm{mRCC}$ case responds to different IFN- $\alpha$ subtypes not only in vitro but also in vivo. There have also been reports that side effects were relieved by changing IFN- $\alpha$ preparations (6). As a strategy for sequential usage of IFN- $\alpha$, we can begin administering any IFN- $\alpha$ and change to any other IFN- $\alpha$ 
as a second line of treatment if the first-line therapy is not effective or harmful. However, it is not yet possible to determine which IFN- $\alpha$ subtype is more effective before treatment in individual cases.

The serum IL-6 level of RCC patients is considered to be associated with malignant potential of the cancer (19). In the present study, IL-6 level was low in all cases in which alternative IFN- $\alpha$ treatment was effective, and there were no effective cases with high IL-6 levels (>2 pg/mL). Serum IL-6 levels were reported to be correlated with serum CRP levels, as in our study $(3,10)$. Low IL-6 level just before alteration of IFN- $\alpha$ is thought to be a good response indicator. Serum IL-6 is not a common laboratory examination but CRP is easily examined as a routine inflammatory index, so serum CRP may be useful as a substitute marker for IL-6 in daily examination. Effective cases were all classified histologically as clear cell cancer, and had only lung and lymph node involvement as metastatic sites $(6,7,9$, $12,16)$. There were no effective cases with two or more MSKCC risk factors.

In conclusion, IFN- $\alpha$ alternation therapy is one treatment option for mRCC patients in whom firstline IFN- $\alpha$ treatment failed if the patient has only lung or lymph node metastasis, low risk factors (MSKCC risk factor 0 or 1), negative for serum $\mathrm{CRP}$, and histologically confirmed clear cell cancer.

\section{REFERENCES}

1. Akaza H, Tsukamoto T, Murai M, Nakajima $\mathrm{K}$ and Naito $\mathrm{S}$ (2007) Phase II study to investigate the efficacy, safety, and pharmacokinetics of sorafenib in Japanese patients with advanced renal cell carcinoma. Jpn J Clin Oncol 37, 755-762.

2. Bellmunt J and Guix M (2009) The medical management of metastatic renal cell carcinoma: integrating new guidelines and recommendations. BJU Int 103, 572-577.

3. Blay JY, Negrier S, Combaret V, Attali S, Goillot E, Merrouche Y, Mercatello A, Ravault A, Tourani JM, Moskovtchenko JF, Philip T and Favrot M (1992) Serum level of interleukin 6 as a prognosis factor in metastatic renal cell carcinoma. Cancer Res 52, 3317-3322.

4. Diaz MO, Bohlander S and Allen G (1996) Nomenclature of the human interferon genes. J Interferon Cytokine Res 16, 179-180.

5. Escudier B, Pluzanska A, Koralewski P, Ravaud A, Bracarda S, Szczylik C, Chevreau C, Filipek M, Melichar B, Bajetta E, Gorbunova V, Bay JO, Bodrogi I, Jagiello-Gruszfeld A and Moore N (2007) Bevacizumab plus interferon alfa-2a for treatment of metastatic renal cell carcinoma: a randomised, double-blind phase III trial. Lancet 370, 2103-2111.

6. Fujita K, Tanaka M, Kaneko T, Nagata T and Homma Y (2007) Pulmonary metastasis of renal cell carcinoma with different responses to two kinds of natural interferon-alpha. Rinsho Hinyokika 61, 749-752.

7. Horiguchi A and Uchida A (2004) Advanced renal cell carcinoma showing a different response to two types of interfer- on-alpha. Nihon Hinyokika Gakkai Zasshi 95, 50-53.

8. Ito N, Eto M, Nakamura E, Takahashi A, Tsukamoto T, Toma H, Nakazawa H, Hirao Y, Uemura H, Kagawa S, Kanayama H, Nose Y, Kinukawa N, Nakamura T, Jinnai N, Seki T, Takamatsu M, Masui Y, Naito S and Ogawa O (2007) STAT3 polymorphism predicts interferon-alfa response in patients with metastatic renal cell carcinoma. J Clin Oncol 25, 27852791.

9. Kato Y, Saga Y, Hori J, Hashimoto H and Kakizaki H (2006) Case report of advanced renal cancer that showed different responses to the alteration of therapeutic cytokines. Nihon Hinyokika Gakkai Zasshi 97, 598-601.

10. Ljungberg B, Grankvist K and Rasmuson T (1997) Serum interleukin-6 in relation to acute-phase reactants and survival in patients with renal cell carcinoma. Eur $J$ Cancer 33, 1794-1798.

11. Medical Research Council Renal Cancer Collaborators (1999) Interferon-alpha and survival in metastatic renal carcinoma: early results of a randomised controlled trial. Lancet 353, 14-17.

12. Miwa S, Kadono Y, Sugata T, Mizokami A and Namiki M (2010) Successful treatment for metastases from renal cell carcinoma with alternation of interferon-alpha subtypes. Int $J$ Clin Oncol 15, 97-100.

13. Motzer RJ, Hutson TE, Tomczak P, Michaelson MD, Bukowski RM, Rixe O, Oudard S, Negrier S, Szczylik C, Kim ST, Chen I, Bycott PW, Baum CM and Figlin RA (2007) Sunitinib versus interferon alfa in metastatic renal-cell carcinoma. $N$ Engl J Med 356, 115-124.

14. Naito S, Yamamoto N, Takayama T, Muramoto M, Shinohara N, Nishiyama K, Takahashi A, Maruyama R, Saika T, Hoshi S, Nagao K, Yamamoto S, Sugimura I, Uemura H, Koga S, Takahashi M, Ito F, Ozono S, Terachi T and Tomita Y (2010) Prognosis of Japanese metastatic renal cell carcinoma patients in the cytokine era: a cooperative group report of 1463 patients. Eur Urol 57, 317-325.

15. Negrier S, Escudier B, Lasset C, Douillard JY, Savary J, Chevreau C, Ravaud A, Mercatello A, Peny J, Mousseau M, Philip T and Tursz T (1998) Recombinant human interleukin-2, recombinant human interferon alfa-2a, or both in metastatic renal-cell carcinoma. N Engl J Med 338, 1272-1278.

16. Oya M, Asakura H, Mizuno R, Marumo K and Murai M (2005) Repeated regression of pulmonary metastases from renal cell carcinoma after treatment using different interferon-alpha preparations. Biomed Res 26, 135-137.

17. Rini BI, Halabi S, Rosenberg JE, Stadler WM, Vaena DA, Ou SS, Archer L, Atkins JN, Picus J, Czaykowski P, Dutcher $\mathrm{J}$ and Small EJ (2008) Bevacizumab plus interferon alfa compared with interferon alfa monotherapy in patients with metastatic renal cell carcinoma: CALGB 90206. J Clin Oncol 26, 5422-5428.

18. Steis RG, Smith JW, 2nd Urba WJ, Clark JW, Itri LM, Evans LM, Schoenberger C and Longo DL (1988) Resistance to recombinant interferon alfa-2a in hairy-cell leukemia associated with neutralizing anti-interferon antibodies. $N$ Engl $J$ Med 318, 1409-1413.

19. Thiounn N, Pages F, Flam T, Tartour E, Mosseri V, Zerbib M, Beuzeboc P, Deneux L, Fridman WH and Debre B (1997) IL-6 is a survival prognostic factor in renal cell carcinoma. Immunol Lett 58, 121-124.

20. Uemura H, Shinohara N, Yuasa T, Tomita Y, Fujimoto H, Niwakawa M, Mugiya S, Miki T, Nonomura N, Takahashi M, Hasegawa Y, Agata N, Houk B, Naito S and Akaza H (2010) A phase II study of sunitinib in Japanese patients with meta- 
static renal cell carcinoma: insights into the treatment, efficacy and safety. Jpn J Clin Oncol 40, 194-202.

21. Vuky J and Motzer RJ (2000) Cytokine therapy in renal cell cancer. Urol Oncol 5, 249-257.

22. Yamaoka T, Kojima S, Ichi S, Kashiwazaki Y, Koide T and Sokawa Y (1999) Biologic and binding activities of IFNalpha subtypes in ACHN human renal cell carcinoma cells and Daudi Burkitt's lymphoma cells. J Interferon Cytokine Res 19, 1343-1349.
23. Yanai Y, Horie S, Yamamoto $\mathrm{K}$, Yamauchi H, Ikegami H, Kurimoto $\mathrm{M}$ and Kitamura T (2001) Characterization of the antitumor activities of IFN-alpha8 on renal cell carcinoma cells in vitro. J Interferon Cytokine Res 21, 1129-1136.

24. Yanai Y, Sanou O, Yamamoto K, Yamauchi H, Ikegami H and Kurimoto M (2002) The anti-tumor activities of interferon (IFN)-alpha in chronic myelogenous leukaemia (CML)derived cell lines depends on the IFN-alpha subtypes. Cancer Lett 185, 173-179. 